\title{
Norepinephrine Is Necessary for Experience-Dependent Plasticity in the Developing Mouse Auditory Cortex
}

\author{
Kathryn N. Shepard, ${ }^{1,2}$ L. Cameron Liles, ${ }^{3}$ David Weinshenker, ${ }^{1,3}$ and Robert C. Liu ${ }^{1,2}$ \\ ${ }^{1}$ Graduate Program in Neuroscience, ${ }^{2}$ Department of Biology, and ${ }^{3}$ Department of Human Genetics, Emory University, Atlanta, Georgia 30322
}

Critical periods are developmental windows during which the stimuli an animal encounters can reshape response properties in the affected system to a profound degree. Despite this window's importance, the neural mechanisms that regulate it are not completely understood. Pioneering studies in visual cortex initially indicated that norepinephrine (NE) permits ocular dominance column plasticity during the critical period, but later research has suggested otherwise. More recent work implicating NE in experience-dependent plasticity in the adult auditory cortex led us to re-examine the role of NE in critical period plasticity. Here, we exposed dopamine $\beta$-hydroxylase knock-out $\left(D b h^{-I-}\right)$ mice, which lack NE completely from birth, to a biased acoustic environment during the auditory cortical critical period. This manipulation led to a redistribution of best frequencies (BFs) across auditory cortex in our control mice, consistent with prior work. By contrast, $D b h^{-1-}$ mice failed to exhibit the expected redistribution of BFs, even though NE-deficient and NE-competent mice showed comparable auditory cortical organization when reared in a quiet colony environment. These data suggest that while intrinsic tonotopic patterning of auditory cortical circuitry occurs independently from NE, NE is required for critical period plasticity in auditory cortex.

Key words: auditory cortex; critical period; norepinephrine; sound exposure; tonotopy

\section{Introduction}

Sensory systems often undergo critical periods during postnatal development, during which neural response properties can be easily reshaped by sensory experience. The pioneering work of Hubel and Wiesel, for example, showed that the proportion of visual cortex responding to stimulation of a previously occluded eye could be reduced if occlusion occurred during a circumscribed period of development (Wiesel and Hubel, 1963). In the wake of Hubel and Wiesel's findings, such critical periods have also been described for the auditory (Zhang et al., 2001; de Villers-Sidani et al., 2007), somatosensory (Fox, 1992; Crair and Malenka, 1995), and vestibular (Jones et al., 2000; Moorman et al., 2002) systems.

Early studies by Pettigrew and colleagues indicated that norepinephrine (NE) was necessary for critical period plasticity. Depleting it from kitten visual cortex inhibited the shift in responsiveness toward the unoccluded eye following monocular occlusion (Kasamatsu and Pettigrew, 1976; Daw et al., 1983), and replenishing it during the critical period restored plasticity (Kasa-

\footnotetext{
Received Feb. 6, 2014; revised Dec. 15, 2014; accepted Dec. 22, 2014.

Author contributions: K.N.S., D.W., and R.C.L. designed research; K.N.S. and L.C.L. performed research; K.N.S. analyzed data; K.N.S., D.W., and R.C.L. wrote the paper.

This work was supported by National Institutes of Health Grants F31 DC011987 (K.N.S.), R01 DC008343 (R.C.L.), and R01 DA027535 (D.W.), and Emory University's PRISM (Problems and Research to Integrate Science \& Mathematics) Fellowship DGE0536941, a GK-12 program of the National Science Foundation (K.N.S.). We also thank Sarah Pallas for her feedback on the manuscript, and Laura Mariani for technical assistance.

The authors declare no competing financial interests.

Correspondence should be addressed to Robert Liu, Rollins Research Building, Room 2006, 1510 Clifton Road NE, Atlanta, GA 30322. E-mail: robert.liu@emory.edu.

DOI:10.1523/JNEUROSCI.0532-14.2015

Copyright $\odot 2015$ the authors $\quad 0270-6474 / 15 / 352432-06 \$ 15.00 / 0$
}

matsu et al., 1979). However, subsequent studies reported that lesioning either the noradrenergic or cholinergic system alone failed to block plasticity (Bear and Daniels, 1983; Adrien et al., 1985), suggesting functional redundancy between the two systems (Bear and Singer, 1986).

NE's involvement in critical period regulation remains unclear today, though more recent studies have implicated NE in experience-dependent plasticity in the adult auditory cortex (Edeline et al., 2011; Martins and Froemke, 2013). This motivated us to revisit NE's involvement in experience-dependent developmental plasticity, using the auditory cortex of the NEdeficient $D b h^{-1-}$ mouse as our model. In these mice, we attempted to drive the redistribution of best frequencies $(\mathrm{BFs})$ in the auditory cortical frequency map through pure tone exposure during the critical period (Zhang et al., 2001; de Villers-Sidani et al., 2007; Insanally et al., 2009). We found that while auditory cortical organization was comparable between unperturbed $D b h^{-1-}$ mice and controls, critical period plasticity was inhibited in $D b h^{-1-}$ mice, suggesting that NE is required for frequency map plasticity in the auditory cortical critical period.

\section{Materials and Methods}

All procedures were approved by the Emory Institutional Animal Care and Use Committee. Electrophysiological recordings were taken from 6-8-week-old female $\mathrm{Dbh}^{-1-}$ mice bred on a mixed C57BL/6J and 129SvEv background (Research Resource Identifier: MGI:1857556). Because NE deficiency is fatal to embryonic $D b h^{-1-}$ mice (Thomas et al., 1995), the NE precursor L-3,4-dihydroxyphenylserine (L-DOPS) was administered via maternal drinking water from embryonic day 14.5 until birth. This intervention allows $D b h^{-1-}$ embryos to synthesize enough NE for normal fetal development (Thomas et al., 1998). Once born, $\mathrm{Dbh}^{-1-}$ mice do not require L-DOPS for survival despite complete NE 
deficiency. Furthermore, other than lacking NE, their noradrenergic system is largely comparable to NE-competent controls (Weinshenker et al., 2002a; Jin et al., 2004). $D b h^{+/-}$littermates, which are heterozygous for the dopamine $\beta$-hydroxylase gene and have NE levels comparable to wild-type $\left(D b h^{+/+}\right)$mice (Thomas et al., 1998; Bourdélat-Parks et al., 2005; Sanders et al., 2006), were used as controls.

"Baseline" animals of both genotypes were housed in a standard colony environment until electrophysiological recording between postnatal day (P) 42 and P56. " 8 kHz-exposed" animals of both genotypes were housed in this colony except during sound exposure. That occurred in a sound-attenuating chamber (IAC Acoustics) for 16-18 h/d from P7 to $\mathrm{P} 21$, which encompasses the P12-P15 critical period for frequency tuning, as defined in the C57BL/6J mouse (Barkat et al., 2011). Stimuli consisted of $8 \mathrm{kHz}$ pure tones $(80 \mathrm{~dB}$ SPL, $100 \mathrm{~ms}, 1 \mathrm{~s}$ trains at $5 \mathrm{~Hz}$, alternated with $2 \mathrm{~s}$ silence). A $4 \mathrm{~W}$ white LED bulb and an automatic timer were used to maintain the same light cycle ( $12 \mathrm{~h}$ light/dark) as the colony.

Peripheral hearing thresholds were assessed via auditory brainstem response (ABR). Anesthesia was induced with a 6:1 ketamine $(100 \mathrm{mg} /$ $\mathrm{kg})$ and xylazine $(5 \mathrm{mg} / \mathrm{kg})$ mixture, and maintained with 12:1 ketamine $(30 \mathrm{mg} / \mathrm{kg})$ and xylazine $(1 \mathrm{mg} / \mathrm{kg})$. A presurgical dose of dexamethasone $(10 \mathrm{mg} / \mathrm{kg})$ was given to prevent cortical edema. Needle electrodes were inserted subdermally behind each bulla and at the skull vertex. Signals were sampled at 25 kilosamples/s, amplified 200,000×, and bandpass filtered between 100 and $3000 \mathrm{~Hz}$. ABRs were assessed for clicks and tone pips at $8,16,24$, and $32 \mathrm{kHz}(3 \mathrm{~ms}, 21 \mathrm{~Hz}$ repetition rate), presented through a free-field speaker (HiVi RT1.3 Planar Isodynamic Tweeter). Stimuli were presented at decreasing sound intensities ( $5 \mathrm{~dB}$ interval) until sound-evoked ABR peaks were no longer apparent. ABR waveforms were averaged over 500 stimulus repeats. Off-line, a blinded observer determined the threshold of the ABR's first peak, which represents activity in the auditory nerve. Peak amplitudes were also measured in BioSigRP (Tucker-Davis Technologies) by comparing the height of manually identified ABR peaks to their preceding troughs. Peak I was omitted from analysis because it was not preceded by a trough.

Frequency responses were next mapped electrophysiologically across the left auditory cortex. After removing the muscle over the left parietal bone, a craniotomy was performed and a headpost was cemented to the animal's skull at bregma to maintain a consistent head position throughout the experiment.

Multiunits were recorded across the left auditory cortex using a $4 \mathrm{M} \Omega$ $3 \times 1$ tungsten matrix microelectrode (FHC) with $305 \mu$ m interelectrode spacing. The electrode was driven into layer $4(\sim 400 \mu \mathrm{m})$, and pure tones were played back ( $60 \mathrm{~ms}$, seven intensities from 5 to $65 \mathrm{~dB}$ SPL, 30 frequencies log-spaced $2-32 \mathrm{kHz}$ ) in pseudorandom order, with five repetitions of each frequency-intensity combination. Stimuli were presented with a free-field speaker positioned $20 \mathrm{~cm}$ from and $45^{\circ}$ anterolateral to the right ear. We aimed to capture the entire spatial extent of core auditory cortex, consisting of primary auditory cortex and anterior auditory field. In identifying these, we looked for clear frequency tuning and a peristimulus time histogram (PSTH) peak $<40 \mathrm{~ms}$ from sound onset; weak or unapparent PSTH peaks, or latencies $>40 \mathrm{~ms}$ indicated that a site was outside core auditory cortex. Using vascular features as references, spatial coordinates of each recording site were tracked on a high-resolution photo of the craniotomy.

Offline, frequency response areas (FRAs) were constructed for each multiunit by plotting the magnitude of the response (spikes per second) against the frequency and amplitude of the stimulus. A blinded observer referenced each unit's FRA and PSTH to manually determine its response latency, duration, threshold, and bandwidth at $20 \mathrm{~dB}$ below threshold. BFs were defined as the frequency that generated the highest average spike rate over all the intensities equal to or less than the threshold intensity. Using a method similar to that described in de Villers-Sidani et al. (2007), we also analyzed rate-level functions in an automated fashion. Using custom Matlab code, we found the sound intensity that evoked the strongest response to the BF. Then, using a least-squares method, we fitted a line to the segment of the rate-level function between the loudest sound intensity and the intensity eliciting the peak response. If the peak sound intensity was also the loudest sound intensity, we simply fitted the entire rate-level function. Units with positive slopes were classified as monotonic and units with negative slopes were classified as nonmonotonic.

Individual animals' BF maps were generated by Voronoi tessellation (Matlab: voronoin) of all recording sites for a given animal. Average BF maps were constructed to give a qualitative impression of tonotopic organization within groups. Individual animals' BF maps were normalized such that the rostrocaudal and dorsoventral extents of primary cortex fit a $100 \times 100$ grid, and each grid cell was colored depending on which Voronoi polygon its center would fall within. These "pixelated" maps for each animal within a group were "stacked" and the BFs averaged for each cell in the $z$ direction. If $<6$ maps contributed a BF measurement to a particular cell (i.e., if that normalized location was outside the core auditory cortex for a significant proportion of animals), that cell was excluded from the average map, such that all colored cells display the average $\mathrm{BF}$ at that site for $\geq 6$ animals.

To quantitatively analyze the proportionate area of cortex tuned to a particular frequency band, we used the areas of the (un-normalized) Voronoi polygons tuned to that band, expressed as a proportion of the sum of all core polygons. A fraction of recording sites were associated with polygons of infinite or spuriously large areas because for technical reasons we were unable to "enclose" that area with a perimeter of nonauditory sites. To ensure that these areas did not bias our analyses, we reassigned the median area measurement to the $5 \%$ of sites with the largest areas.

For comparisons between two groups, two-sample $t$ tests were used, provided the data were normally distributed and had equal variance; otherwise, a Mann-Whitney $U$ test was used. For comparisons across all four groups, $2 \times 2$ ANOVAs were used with genotype and rearing condition as factors. To compare best frequency distributions, a two-sample Kolmogorov-Smirnov test was used. The significance level was set to 0.001 to correct for this test's high power, and for the artificially inflated sample size we incurred by pooling multiunits by group. For all other tests, $p<0.05$ was considered significant.

\section{Results}

Because $D b h^{-1-}$ mice experience high rates of ear infection and deafness relative to NE-competent controls (Maison et al., 2010), we performed ABRs to assess hearing thresholds before cortical electrophysiology. Mice that showed clear ABR peaks (Fig. 1A) in response to clicks, $8 \mathrm{kHz}$ tones, and $16 \mathrm{kHz}$ tones were mapped electrophysiologically. Consistent with prior research, more $D b h^{+/-}$(baseline: 9 of $11 ; 8 \mathrm{kHz}$-exposed: 12 of 18 ) than $D b h^{-/-}$ (baseline: 14 of 22; $8 \mathrm{kHz}$-exposed: 13 of 26) mice met these criteria. Among animals that were included, there was no effect of genotype on ABR threshold for peak 1 (Fig. $1 B$; clicks: $F_{\text {geno }}=$ $0.12, p=0.73 ; 8 \mathrm{kHz}: F_{\text {geno }}=0.63, p=0.43 ; 16 \mathrm{kHz}: F_{\text {geno }}=1.2$, $p=0.28)$, which reflects activity in the auditory nerve, for clicks, $8 \mathrm{kHz}$ tones, or $16 \mathrm{kHz}$ tones. Animals that underwent developmental sound exposure had thresholds comparable to baseline (clicks: $F_{\text {experience }}=0.84, p=0.37 ; 8 \mathrm{kHz}: F_{\text {experience }}=1.79, p=$ $\left.0.19 ; 16 \mathrm{kHz}: F_{\text {experience }}=1.92, p=0.18\right)$. Further, no significant interactions between genotype and experience were observed (clicks: $F_{\text {interaction }}=4.18, p=0.05 ; 8 \mathrm{kHz}: F_{\text {interaction }}=2.96, p=$ $0.10 ; 16 \mathrm{kHz}: F_{\text {interaction }}=2.6, p=0.12$ ).

Twenty-four and $32 \mathrm{kHz}$ ABR stimuli were played to these animals, though most animals of both genotypes were deaf to these frequencies at the sound intensities tested ( $\leq 75 \mathrm{~dB}$ SPL). ABRs were also recorded from $D b h^{+/+}$mice (Fig. $1 A, n=3$ ). While thresholds for ABRs evoked by clicks and low-frequency tones were comparable to those seen in $\mathrm{Dbh}^{+/-}$and $\mathrm{Dbh} \mathrm{H}^{-1-}$ mice (clicks: $37 \pm 13 \mathrm{~dB}$ SPL; $8 \mathrm{kHz}: 63 \pm 19 \mathrm{~dB}$ SPL; $16 \mathrm{kHz}$ : $70 \pm 18 \mathrm{~dB}$ SPL), thresholds for 24 and $32 \mathrm{kHz}$ tones were again beyond our loudest tested intensity, indicating that strain background rather than dopamine $\beta$-hydroxylase deficiency is responsible for these animals' limited hearing range. 

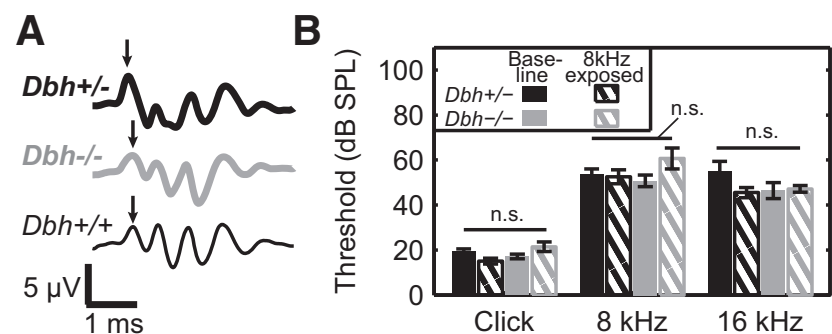

Figure 1. Auditory brainstem responses. A, Representative ABR waveforms for $55 \mathrm{~dB}$ SPL click from individual $D b h^{+/-}, D b h^{-1-}$, and $D b h^{+/+}$mice. Arrows indicate the first ABR peak. $B$, Group average thresholds in response to clicks, $8 \mathrm{kHz}$ tones. and $16 \mathrm{kHz}$ tones. Error bars represent mean $\pm 1 \mathrm{SE}$.

We next characterized auditory cortex in mice reared in a quiet colony environment. Tone-locked responses were obtained from animals in each group (Fig. $2 A, B$, example multiunits), and FRAs (Fig. 2A,B) showed classic V-shaped tuning profiles in $D b h^{+/-}$and $D b h^{-1-}$ animals alike. BFs were estimated, and complete BF maps (i.e., encircled by nonresponsive sites) were constructed for the left auditory cortices of $8 \mathrm{Dbh}^{+/-}$(284 total multiunits) and $7 \mathrm{Dbh}^{-1-}$ (220 total multiunits) mice. Spatial organization of BFs was heterogeneous across mice, and maps were often dominated by sites tuned to $13-16 \mathrm{kHz}$, though a coarse tonotopic frequency gradient could usually be discerned (Fig. 2C,D). Mapping a wild-type mouse confirmed that strain background itself, rather than loss of dopamine $\beta$-hydroxylase, can manifest nonuniform, 13-16 kHz-dominated frequency maps (Fig. 2E). Moreover, averaging maps for a particular group together allowed the expected tonotopic gradient to become more apparent for both $D b h^{+/-}$and $D b h^{-1-}$ mice (Fig. $2 F, G$ ).

Consistent with these qualitative impressions, quantitative comparisons of baseline $\mathrm{Dbh} h^{+/-}$and $\mathrm{Dbh} h^{-/-}$multiunit spatial organization were similar. Total auditory cortex size and the proportion of multiunits tuned to each frequency tested did not differ between groups (Fig. 2H; Kolmogorov-Smirnov test, 0.16; $p>0.001)$. Unit response properties were also not significantly different (Table 1). These data show that, for mice reared in a quiet colony, loss of NE does not appreciably affect the organization of core auditory cortex. Though this suggests NE is not required for the initial patterning of auditory circuitry and its maintenance in an unperturbed environment, it does not preclude the possibility that NE might be involved in adaptation of the auditory cortex to an environmental manipulation during the critical period.

We therefore attempted to drive developmental plasticity directly by altering the acoustic environment during the critical period for frequency tuning in the mouse. Cohorts of mixed $\mathrm{Dbh}^{+/-}$and $\mathrm{Dbh} \mathrm{h}^{-/-}$littermates were exposed to repeated presentations of $8 \mathrm{kHz}$ tones from $\mathrm{P} 7$ to $\mathrm{P} 21$. An $8 \mathrm{kHz}$ frequency was selected for exposure because all animals mapped in our baseline study showed BFs at or around $8 \mathrm{kHz}$, but in no animal was it the most prominent frequency. This provided existing cortical territory to expand into under appropriate conditions, while minimizing the chance of a ceiling effect at the exposure frequency.

Complete BF maps were obtained from $10 \mathrm{Dbh}^{+/-}$(356 total multiunits) and $7 \mathrm{Dbh}^{-1-}$ mice (214 total multiunits). Consistent with prior work, exposure to $8 \mathrm{kHz}$ tones during development drove an approximate doubling of the core cortical area devoted to that frequency in NE-competent animals (Fig. 3C, middle; $8.8 \pm 6.6 \%$ of total auditory cortex area in baseline $D b h^{+/-}$vs $20.5 \pm 8.4 \%$ in $8 \mathrm{kHz}$-exposed $\mathrm{Dbh}^{+/-}$). This effect
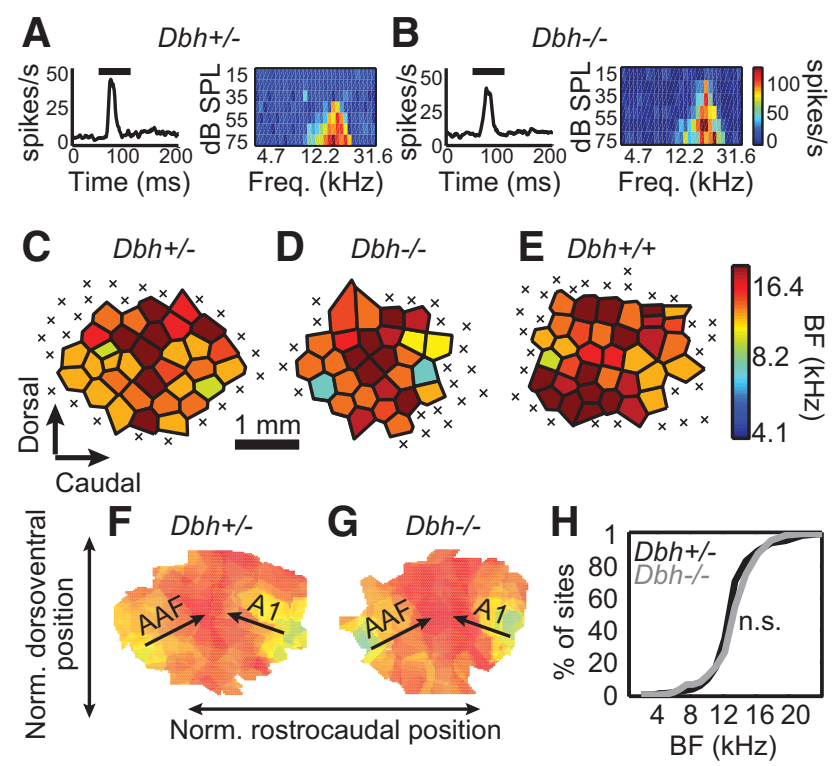

Figure 2. Frequency responses in baseline mice. $A, B$, Representative example PSTHs and FRAs from individual $D b h^{+/-}(\boldsymbol{A})$ and $D b h^{-1-}(\boldsymbol{B})$ multiunits in response to all (pooled) experimental stimuli. In PSTH, black horizontal bar indicates stimulus. $\boldsymbol{C}-\boldsymbol{E}$, Representative BF maps for individual $D b h^{+/-}(\boldsymbol{C}), D b h^{-/-}(\boldsymbol{D})$, and $D b h^{+/+}(\boldsymbol{E})$ mice. Each polygon represents a single multiunit, colored by its BF. X's represent noncore or nonresponsive recording sites. $\boldsymbol{F}, \boldsymbol{G}$, Group average BF maps. Cell color represents the average BF for all constituent maps that have core multiunits at that normalized position. Color scale as in $\boldsymbol{C}-\boldsymbol{E}$. Tonotopic gradients for primary auditory cortex (A1) and anterior auditory field (AAF), shown with arrows. $\boldsymbol{H}$, Cumulative distribution of pooled BFs for each group.

Table 1. Response properties of baseline $D b h^{+/-}$and $D b h^{-/-}$multiunits

\begin{tabular}{lcccc}
\hline Parameter & $D^{\prime} h^{+/-}(n=8)^{a}$ & $D^{-/-}(n=7)^{a}$ & $t$ test & $p$ \\
\hline Latency (ms) & $21 \pm 0.9$ & $21 \pm 0.8$ & 0.07 & 0.94 \\
Duration (ms) & $66 \pm 4.6$ & $71 \pm 6.5$ & 0.65 & 0.53 \\
Threshold (dB SPL) & $33.5 \pm 2.7$ & $34.6 \pm 1.0$ & 0.38 & 0.71 \\
Bandwidth at 20 dB & $1.08 \pm 0.06$ & $0.99 \pm 0.07$ & 1.05 & 0.31 \\
$\quad$ & & & \\
$\quad$ above threshold (octave) & & & 1.06 & 0.31 \\
Spoked at BF (spikes/s) & $90.2 \pm 6.8$ & $81.7 \pm 3.5$ & 0.12 & 0.91 \\
Body mass (g) & $7.4 \pm 1.1$ & $7.3 \pm 0.9$ & 3.56 & 0.004 \\
Auditory cortex size (mm $\left.{ }^{2}\right)^{b}$ & 19.5 & 17.0 & 18 & 0.28 \\
\hline
\end{tabular}

${ }^{a}$ Data in $\mathrm{Dbh}^{+/-}$and $\mathrm{Dbh} \mathrm{h}^{-/-}$columns show pooled multiunit means \pm SEM.

${ }^{b}$ For auditory cortex size, medians are shown and test statistic is Mann-Whitney $U$.

was apparent at the level of individual cortical maps in many cases (Fig. $3 A$ ), as well as in the average map (Fig. $3 B$ ). In contrast, there was no evidence of such an expansion in NE-deficient animals $\left(11.7 \pm 6.6 \%\right.$ of total auditory cortex area in baseline $D b h^{-1-}$ vs $11.5 \pm 7.1 \%$ in $8 \mathrm{kHz}$-exposed $\left.\mathrm{Dbh}^{-l-}\right)$. The proportion of cortex tuned to $8 \mathrm{kHz} \pm 0.35$ octave was not significantly different between exposed and unexposed cohorts of $D b h^{-1-}$ mice. Thus, there was a significant interaction between genotype and experience for the 8 $\mathrm{kHz}$ band $\left(F_{\text {interaction }}=5.09, p=0.03\right)$.

Proportionate area devoted to any frequency band other than $\sim 8 \mathrm{kHz}$ did not differ significantly between exposed and unexposed cohorts, despite a nonsignificant trend for $19.7-31.6 \mathrm{kHz}$, likely arising from random variability in high-frequency hearing. That bin for sound-exposed $D b h^{+/-}$mice contained a slightly higher proportion of animals with higher-frequency hearing limits (by ABR), and these animals also happened to have large cortical representation of those frequencies. In any case, in no bin 

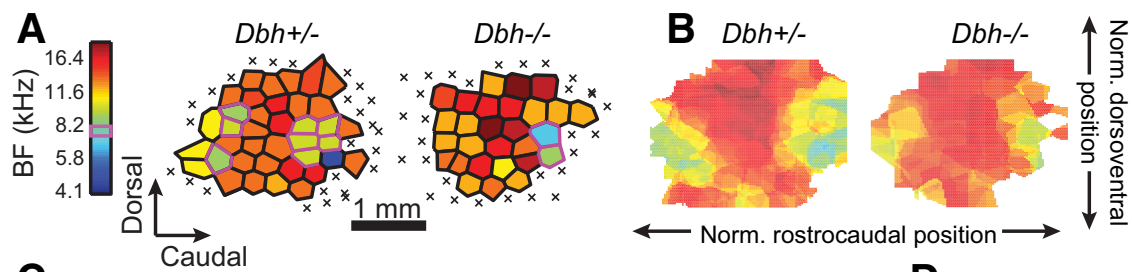
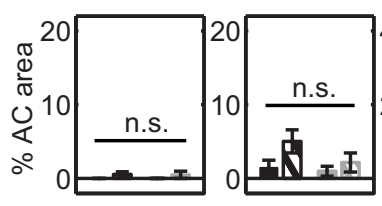

$3.5-5.7$

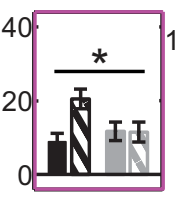

$6.3-10.1$
Best frequency $(\mathrm{kHz})$

Figure 3. Effect of developmental sound exposure on frequency responses in $D b h^{+/-}$and $D b h^{-/-}$mice. $A$, As in Figure $2 C-E$, representative BF maps for individual $8 \mathrm{kHz}$-exposed mice. Magenta outline highlights multiunits with BFs at $8 \mathrm{kHz} \pm 0.35$ octaves. Magenta box on color bar highlights frequency of developmental exposure. $B$, As in Figure $2 F, G$, group average $B F$ maps for $8 \mathrm{kHz}$-exposed mice. Cell color represents the average BF for all constituent maps that have core multiunits at that normalized position. Color scale as in A. C, Percentage area of core auditory cortex ( $A C$ area) tuned within different frequency bins. Each bin contains six tested frequencies, spanning $\sim 0.7$ octaves. Color scheme is same as in Figure $1 B$. Error bars represent means $\pm S E M$. Asterisk indicates significant genotype $\times$ experience interaction, $p<0.05$. D, Bandwidth at $20 \mathrm{~dB}$ above threshold (BW20), for multiunits with characteristic frequencies (CFs) within the specified ranges. "Base." refers to baseline group; "8kHz" refers to 8 $\mathrm{kHz}$-exposed group. Error bars represent means \pm SEM.

Table 2. 8 kHz tone-evoked ABR peak amplitudes ${ }^{a}$

\begin{tabular}{|c|c|c|c|c|c|c|}
\hline & \multicolumn{2}{|l|}{ Baseline } & \multicolumn{2}{|c|}{$8 \mathrm{kHz}$-exposed } & \multirow[b]{2}{*}{$F_{\text {interaction }}$} & \multirow[b]{2}{*}{$p$} \\
\hline & $\mathrm{Dbh}^{+/-}$ & $D b h^{-/-}$ & $\mathrm{Dbh}^{+/-}$ & $D b h^{-/-}$ & & \\
\hline Peak II (nV) & 898 & 873 & 1077 & 772 & 0.81 & 0.38 \\
\hline Peak III (nV) & 261 & 348 & 541 & 182 & 2.83 & 0.11 \\
\hline Peak IV (nV) & 2049 & 2191 & 1871 & 1582 & 0.42 & 0.53 \\
\hline Peak V (nV) & 1701 & 1153 & 871 & 1011 & 1.9 & 0.18 \\
\hline
\end{tabular}

${ }^{a}$ Statistical results are reported for genotype $\times$ experience ANOVAs conducted for each peak.

besides $8 \mathrm{kHz}$ was a significant interaction observed for genotype and rearing experience $\left(2-3.39 \mathrm{kHz}\right.$ band: $F_{\text {interaction }}=0.01, p=$ $0.93 ; 3.4-5.99 \mathrm{kHz}$ band: $F_{\text {interaction }}=0.84, p=0.37 ; 10.5-18.73$ kHz band: $F_{\text {interaction }}=3.52, p=0.07 ; 19.7-31.6 \mathrm{kHz}$ band: $F_{\text {in }}{ }^{-}$ teraction $=1.01, p=0.32$ ). The specificity of our plasticity effects for the band of exposure therefore implicates NE as a regulator of experience-dependent cortical map plasticity during the critical period.

Additional evidence was sought to determine the specificity of this plasticity to the auditory cortical map. We found that peak amplitudes of $8 \mathrm{kHz}$ tone-evoked ABRs, which are generated subcortically, lacked significant genotype $\times$ experience interactions (Table 2). This indicates that plasticity for the exposed frequency is restricted to the cortex. That cortical multiunit firing rates in response to $8 \mathrm{kHz}$ tones are also comparable across groups (baseline $D b h^{+/-}: 26.8 \pm 27.2$ spikes/s; baseline $D b h^{-1-}: 24.9 \pm 27.0$ spikes/s; $8 \mathrm{kHz}$-exposed $D b h^{+/-}: 26.4 \pm$ 25.1 spikes $/ \mathrm{s} ; 8 \mathrm{kHz}$-exposed $D b h^{-1-}: 27.1 \pm 23.3$ spikes $/ \mathrm{s} ; F_{\text {in }}{ }^{-}$ teraction $=0.60, p=0.44$ ) further suggests plasticity just at the level of the cortical map.

Finally, we examined our results further to assess whether some previously characterized forms of developmental exposureinduced plasticity were expressed in our model. We first turned to tuning bandwidth, as others have observed changes in this response parameter following developmental sound exposure (Han et al., 2007; de Villers-Sidani et al., 2007). We focused on multiunits tuned to the $8 \mathrm{kHz}$ bin of exposure $(6.3-10.1 \mathrm{kHz})$,

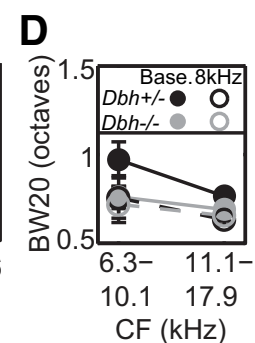

and the adjacent higher-frequency bin $(11.1-17.9 \mathrm{kHz})$ that contained the large majority of the rest of the multiunits. Bandwidths were indeed narrower in sound-exposed $\mathrm{Dbh}^{+/-}$animals (Fig. 3D; $F_{\text {experience }}=10.68, p=0.001$ ), though this was not specific for the sound-exposed frequency bin $\left(F_{\text {interaction }}=0.6, p=0.44\right)$, as Han et al. (2007) showed. In $D b h^{-1-}$ mice, we did not find evidence of an effect of sound exposure on bandwidth either across all frequencies $\left(F_{\text {experience }}=0.31\right.$, $p=0.58)$, or in a frequency-dependent manner $\left(F_{\text {interaction }}<0.01, p=0.95\right)$. This echoes the pattern of plasticity we observed for frequency tuning, in which sound exposure-dependent changes were observed in NE-competent $D b h^{+/-}$mice, but not NE-deficient $D b h^{-1-}$ mice. We next compared the proportions of $\mathrm{Dbh}$ $+/-$ units showing monotonic versus nonmonotonic rate-level functions, as in de Villers-Sidani et al. (2007). Consistent with that study, most of the units recorded from both baseline and sound-exposed mice showed monotonic rate-level functions. Unlike de Villers-Sidani et al., though, we observed only a slight and nonsignificant increase in the proportion of nonmonotonic rate-level functions in sound-exposed animals (baseline $\mathrm{Dbh}^{+/-}:$:35\%; $8 \mathrm{kHz}$-exposed $D b h^{+/-}$: 39\%; two-sample $z$ test, $z=1.04, p=0.29$ ). Because no significant effect was observed for the $D b h^{+/-}$mouse, we did not extend our investigation to the $D b h^{-1-}$ groups. Thus, the clear map plasticity observed in $D b h^{+/-}$mice is accompanied by a nonfrequencyspecific narrowing of tuning bandwidths, but not a change in rate-level function.

\section{Discussion}

Here, we sought to re-examine whether NE is required for critical period plasticity using the core auditory cortex of NE-deficient $D b h^{-1-}$ mice as our model. We found that while the baseline organization of auditory cortex in the $\mathrm{Dbh}^{-1-}$ mouse was comparable to that of its $D b h^{+/-}$counterparts, we were unable to drive a redistribution of BFs by exposing these animals to a biased acoustic environment during development. This effect was not accompanied by changes in the cortical or subcortical magnitude of the response to the stimulus of exposure. This implies that NE is required for plasticity during the critical period for frequency tuning in the auditory cortical map.

A number of prior studies in visual cortex have argued against the necessity of NE for critical period plasticity (Bear and Daniels, 1983; Adrien et al., 1985; Bear and Singer, 1986). One possible reason for this discrepancy is these studies' use of neurotoxins, particularly 6-hydroxydopamine (6-OHDA), to destroy noradrenergic neurons. 6-OHDA is somewhat nonspecific, as it kills dopaminergic (Uretsky and Iversen, 1970; Walker et al., 2013) as well as noradrenergic neurons, and acutely compromises cholinergic signaling (Bear and Singer, 1986). Further, depending on the route of administration and dosage, 6-OHDA lesions may not include all noradrenergic projections in the area of interest.

The $\mathrm{Dbh}^{-1-}$ mouse does not carry these risks of nonspecificity and incompletion, but its use here does introduce some 
caveats. First, $D b h^{-1-}$ mice experience delayed growth through approximately week 5 of postnatal development (Thomas et al., 1995), raising the possibility that critical period plasticity could be delayed, rather than blocked, in these mice. Our long duration of sound exposure deliberately overshoots the critical period in the mouse (Barkat et al., 2011) by $\sim 1$ week to largely protect against the possibility that the critical period occurs later. It could also be that closure of the critical period window is delayed in these mice, and that between finishing developmental sound exposure and adult mapping, their tonotopic maps renormalize. In principle, this could be addressed by mapping animals immediately after sound exposure. However, completing anesthetized mapping studies in 3-week-old $\mathrm{Dbh}^{-1-}$ mice is very difficult technically due to their small size and fragility. In any case, that renormalization does not apparently happen in $\mathrm{Dbh}^{+/-}$mice would still indicate a difference in plasticity mechanisms.

Second, $\mathrm{Dbh}^{-1-}$ mice show hypersensitive dopaminergic signaling in some regions, raising the question of whether this or the primary NE deficit is responsible for the observed plasticity phenotype. This seems unlikely as dopaminergic signaling abnormalities were restricted to the striatum and not present in neocortex (Weinshenker et al., 2002b; Schank et al., 2006). Nevertheless, a NE replacement study, though experimentally challenging, would help rule out the possibility that dopamine is responsible for the effect we observed. We note though that stimulating the dopaminergic system during sound exposure in adult rodents actually induces map expansion (Bao et al., 2001), making it less likely that this mechanism explains the lack of plasticity in our $D b h^{-1-}$ mice.

Finally, since NE loss is systemic in the $D b h^{-1-}$ mouse, our results do not elucidate the site at which NE acts to enable developmental plasticity. Replacing NE in the auditory cortex of the $D b h^{-1-}$ mouse during the critical period would help determine whether NE's action is direct or indirect, though achieving this pharmacologically is difficult because mouse pups are so small and fragile. A site-specific, conditional $D b h$ knock-out that permits DBH synthesis only in cortex, and only during early postnatal development, could provide more definitive results, but would also be more technically challenging to produce.

It is appealing to speculate that, if NE acts directly on the auditory cortex to enable critical period map plasticity, it does so by gating or facilitating the synaptic plasticity events that likely underlie map plasticity. There is ample evidence of noradrenergic involvement in synaptic plasticity: in other systems, NE has been shown to facilitate synaptic plasticity directly through its actions on AMPA receptor trafficking (Hu et al., 2007; Liu et al., 2010) and neurotransmitter release (Carey and Regehr, 2009). It also permits long-term potentiation in thalamorecipient neurons in the amygdala indirectly by reducing GABAergic inhibition of these cells (Tully et al., 2007). The precise synaptic changes that ultimately produce map plasticity have not yet been characterized, but recent in vitro work suggests there is a critical period for plasticity in layer IV thalamocortical synapses that occurs concurrently with and potentially underlies the critical period for map plasticity in auditory cortex (Barkat et al., 2011). Follow-up work assessing the necessity of NE for this critical period for thalamocortical connectivity could be useful for not only identifying the substrate upon which NE acts to enable map plasticity, but could also for further clarifying the extent to which the critical periods for map plasticity and thalamocortical connectivity share common mechanisms.

\section{References}

Adrien J, Blanc G, Buisseret P, Frégnac Y, Gary-Bobo E, Imbert M, Tassin JP, Trotter Y (1985) Noradrenaline and functional plasticity in kitten visual cortex: a re-examination. J Physiol 367:73-98. CrossRef Medline

Bao S, Chan VT, Merzenich MM (2001) Cortical remodelling induced by activity of ventral tegmental dopamine neurons. Nature 412:79-83. CrossRef Medline

Barkat TR, Polley DB, Hensch TK (2011) A critical period for auditory thalamocortical connectivity. Nat Neurosci 14:1189-1194. CrossRef Medline

Bear MF, Daniels JD (1983) The plastic response to monocular deprivation persists in kitten visual cortex after chronic depletion of norepinephrine. J Neurosci 3:407-416. Medline

Bear MF, Singer W (1986) Modulation of visual cortical plasticity by acetylcholine and noradrenaline. Nature 320:172-176. CrossRef Medline

Bourdélat-Parks BN, Anderson GM, Donaldson ZR, Weiss JM, Bonsall RW, Emery MS, Liles LC, Weinshenker D (2005) Effects of dopamine betahydroxylase genotype and disulfiram inhibition on catecholamine homeostasis in mice. Psychopharmacology (Berl) 183:72-80. CrossRef Medline

Carey MR, Regehr WG (2009) Noradrenergic control of associative synaptic plasticity by selective modulation of instructive signals. Neuron 62 : 112-122. CrossRef Medline

Crair MC, Malenka RC (1995) A critical period for long-term potentiation at thalamocortical synapses. Nature 375:325-328. CrossRef Medline

Daw NW, Rader RK, Robertson TW, ArielM (1983) Effects of6-hydroxydopamine on visual deprivation in the kitten striate cortex. J Neurosci 3:907-914. Medline

de Villers-Sidani E, Chang EF, Bao S, Merzenich MM (2007) Critical period window for spectral tuning defined in the primary auditory cortex (A1) in the rat. J Neurosci 27:180-189. CrossRef Medline

Edeline JM, Manunta Y, Hennevin E (2011) Induction of selective plasticity in the frequency tuning of auditory cortex and auditory thalamus neurons by locus coeruleus stimulation. Hear Res 274:75-84. CrossRef Medline

Fox K (1992) A critical period for experience-dependent synaptic plasticity in rat barrel cortex. J Neurosci 12:1826-1838. Medline

Han YK, Köver H, Insanally MN, Semerdjian JH, Bao S (2007) Early experience impairs perceptual discrimination. Nat Neurosci 10:1191-1197. CrossRef Medline

Hu H, Real E, Takamiya K, Kang MG, Ledoux J, Huganir RL, Malinow R (2007) Emotion enhances learning via norepinephrine regulation of AMPA-receptor trafficking. Cell 131:160-173. CrossRef Medline

Insanally MN, Köver H, Kim H, Bao S (2009) Feature-dependent sensitive periods in the development of complex sound representation. J Neurosci 29:5456-5462. CrossRef Medline

Jin SH, Kim HJ, Harris DC, Thomas SA (2004) Postnatal development of the cerebellum and the CNS adrenergic system is independent of norepinephrine and epinephrine. J Comp Neurol 477:300-309. CrossRef Medline

Jones SM, Warren LE, Shukla R, Browning A, Fuller CA, Jones TA (2000) The effects of hypergravity and substrate vibration on vestibular function in developing chickens. J Gravit Physiol 7:31-44. Medline

Kasamatsu T, Pettigrew JD (1976) Depletion of brain catecholamines: failure of ocular dominance shift after monocular occlusion in kittens. Science 194:206-209. CrossRef Medline

Kasamatsu T, Pettigrew JD, Ary M (1979) Restoration of visual cortical plasticity by local microperfusion of norepinephrine. J Comp Neurol 185 : 163-181. CrossRef Medline

Liu Y, Formisano L, Savtchouk I, Takayasu Y, Szabó G, Zukin RS, Liu SJ (2010) A single fear-inducing stimulus induces a transcription-dependent switch in synaptic AMPAR phenotype. Nat Neurosci 13:223-231. CrossRef Medline

Maison SF, Le M, Larsen E, Lee SK, Rosowski JJ, Thomas SA, Liberman MC (2010) Mice lacking adrenergic signaling have normal cochlear responses and normal resistance to acoustic injury but enhanced susceptibility to middle-ear infection. J Assoc Res Otolaryngol 11:449-461. CrossRef Medline

Martins A, Froemke RC (2013) Neuromodulatory plasticity governs cortical plasticity. Presented at the Society for Neuroscience Annual Meeting, San Diego, November.

Moorman SJ, Cordova R, Davies SA (2002) A critical period for functional vestibular development in zebrafish. Dev Dyn 223:285-291. CrossRef Medline

Sanders JD, Szot P, Weinshenker D, Happe HK, Bylund DB, Murrin LC 
(2006) Analysis of brain adrenergic receptors in dopamine-betahydroxylase knockout mice. Brain Res 1109:45-53. CrossRef Medline

Schank JR, Ventura R, Puglisi-Allegra S, Alcaro A, Cole CD, Liles LC, Seeman P, Weinshenker D (2006) Dopamine beta-hydroxylase knockout mice have alterations in dopamine signaling and are hypersensitive to cocaine. Neuropsychopharmacology 31:2221-2230. Medline

Thomas SA, Matsumoto AM, Palmiter RD (1995) Noradrenaline is essential for mouse fetal development. Nature 374:643-646. CrossRef Medline

Thomas SA, Marck BT, Palmiter RD, Matsumoto AM (1998) Restoration of norepinephrine and reversal of phenotypes in mice lacking dopamine beta-hydroxylase. J Neurochem 70:2468-2476. Medline

Tully K, Li Y, Tsvetkov E, Bolshakov VY (2007) Norepinephrine enables the induction of associative long-term potentiation at thalamo-amygdala synapses. Proc Natl Acad Sci U S A 104:14146-14150. CrossRef Medline

Uretsky NJ, Iversen LL (1970) Effects of 6-hydroxydopamine on catecholamine containing neurones in the rat brain. J Neurochem 17:269-278. CrossRef Medline
Walker MD, Dinelle K, Kornelsen R, Lee A, Farrer MJ, Stoessl AJ, Sossi V (2013) Measuring dopaminergic function in the 6-OHDA-lesioned rat: a comparison of PET and microdialysis. EJNMMI Res 3:69. CrossRef Medline

Weinshenker D, White SS, Javors MA, Palmiter RD, Szot P (2002a) Regulation of norepinephrine transporter abundance by catecholamines and desipramine in vivo. Brain Res 946:239-246. CrossRef Medline

Weinshenker D, Miller NS, Blizinsky K, Laughlin ML, Palmiter RD (2002b) Mice with norepinephrine deficiency resemble amphetaminesensitized animals. Proc Natl Acad Sci U S A 99:13873-13877. CrossRef Medline

Wiesel TN, Hubel DH (1963) Single-cell response in striate cortex of kittens deprived of vision in one eye. J Neurophysiol 26:1003-1017. Medline

Zhang LI, Bao S, Merzenich MM (2001) Persistent and specific influences of early acoustic environments on primary auditory cortex. Nat Neurosci 4:1123-1130. CrossRef Medline 